\title{
Prevention and management of false memory syndrome
}

\author{
Harold Merskey
}

As with most issues in medicine, the prevention and management of a problem is best understood when the origins are known. The term 'false memory syndrome' (FMS) came into use in March 1992 with the foundation of the False Memory Syndrome Foundation (FMSF), a non-profit-making organisation established in the USA by a group of families in which one or more of the parents was accused. The parents in these families were reacting to a phenomenon which developed in a characteristic form in the preceding decade and had become common enough by 1991 for a number of them to realise that they were not alone, and to join in setting up the Foundation with a professional and scientific advisory board.

\section{Presentation}

Typically, sufferers from FMS are female, usually participating in some type of psychotherapy, who report sexual abuse in childhood which it is claimed has been forgotten and only recovered in adult life. Commonly, it is claimed that the alleged abuse has been repressed for periods ranging from 8 to 40 years.

Box 1. Accusers and accused

False memories most often occur in women Typically, repression is alleged for 8-40 years Fathers and male connections (stepfathers or brothers) are most often accused

In the False Memory Syndrome Foundation cases $30 \%$ of the mothers were accused
The accused person is most often the father or another relative. In $30 \%$ of cases in a survey undertaken by the FMSF (1993), mothers were accused of participating in the activity, as well as fathers (see Box 1). These memories do not appear as a rule until the person is exposed to some type of suggestion. Some of the striking features of the modal pattern of FMS include frequent discovery of 'memories' from before the age of three years (a biological impossibility); diagnoses of multiple personality disorder alleged to be related to sexual abuse, but only discovered after the start of treatment; and bizarre claims of having been involved in multi-generational satanic ritual abuse, with the breeding of foetuses or babies for sacrifice and cannibalism. The development of recovered memories extended to one report of being anxious in the course of passage through the fallopian tubes, claims of regression to past lives and belief in abductions by aliens from outer space.

\section{Development through suggestion}

The individuals who attracted the most attention originally appeared to be from middle-class families and were well-educated. They entered treatment for a variety of reasons: symptoms of depression or anxiety, poorly explained pains and other bodily complaints, eating disorders, alcohol misuse, difficulties in marriage or after a divorce, bereavement and so on. In the hands of therapists who believed in searching for repressed memories of childhood abuse, the individual was encouraged to recall such events. If memories did not come quickly,

Harold Merskey (London Health Sciences Centre, University Campus, 339 Windermere Avenue, London, Ontario N6A 5A5, Canada), Professor Emeritus of Psychiatry at the University of Western Ontario, graduated MA, BMBCh in 1953 and DM 1965. He is particularly interested in body-mind relationships, and has published extensively on pain, hysteria and other topics including psychiatric ethics. 
more pressure was exerted. Once a memory developed the person was told to stay away from members of the family, until they acknowledged their wickedness and guilt, and law suits might be commenced to pay for the damage done and for further therapy. Families were torn apart (and still are) by uncorroborated evidence, based upon solicited recall by individuals who had had no knowledge, for 10 years or more, of the events said to have taken place (see Box 2).

The leading feature which distinguished this therapy from dynamic exploratory psychotherapy as it has usually been practised before was an insistence on the part of most of the therapists, if not all, that the symptoms - whatever their nature could only have been due to childhood sexual abuse, whether remembered or not. If not remembered, it had to be recovered. Sometimes this strong suggestion came from reading the book The Courage to Heal (Bass \& Davis, 1988), either before the person was participating in therapy or on the recommendation of the therapist. This book, which is consistently dedicated to recovering supposed memories of abuse and dealing with them, includes notorious statements such as:

"If you don't remember your abuse you are not alone. Many women don't have memories, and some never get memories. This doesn't mean they weren't abused" (p. 81)

and

"If you don't have any memory of it, it can be hard to believe the abuse really happened" (p. 82).

This book is by two creative writers with no professional training in the fields of psychology or psychotherapy, and soon after its initial publication in 1988 had sold over 750000 copies.

Suggestive methods of treatment frequently employed (Box 3) include hypnosis, guided imagery, dream interpretation and narcoanalysis. Group treatment with others claiming to be survivors is common in people with FMS and includes membership in survivor groups, attendance at women's centres and participation in groups for adult children of people with alcohol dependency. With these

Box 2. The search for memory

First cases appeared in psychotherapy

Subjects were well-educated, with welladjusted families

Suggestions were frequent and often forceful

The search for memories was promoted recklessly

Reconciliation was rejected and confrontation demanded

\section{Box 3. Suggestive influences}

Dream interpretation

Hypnosis

Guided imagery

Survivors' groups

Groups for adult children of parents with alcohol dependency

methods and in these settings, the special feature is the emphasis not merely on finding material by psychotherapy, but on the therapist actively helping the patient to determine what shows the occurrence of abuse. Lesser degrees of suggestion include being treated in regular psychotherapy sessions or regular 'therapy' sessions where the therapist expects certain results and conveys the expectation consistently to the service user; even these have been very powerful in producing false memories.

\section{Spread of accusations}

False memory syndrome is not a diagnostic category as such, but is accurately described as a syndrome in terms of a number of features occurring together. As knowledge about it has spread, it has become recognised that laying claim to having discovered repressed memories in therapy may hinder acceptance of allegations of sexual abuse. Hence, histories and accusations that began as claims of recovered memory have tended to be revised, and statements have been made that the items in question were always remembered.

Another field in which false accusations have proliferated as a form of mass hysteria (epidemic non-organic symptoms or ideas of illness) is found in nursery day care (see Box 4) where care-givers have been subjected to the most grave and bizarre accusations and a number have been convicted. In North America many, but not all, of these cases have been overturned by now or are under appeal. If individuals were not convicted, their families nevertheless suffered great disruption as in the Cleveland and Orkney cases in Britain. Pendergrast (1997) describes a number of the most flagrant cases in North America and the UK.

Common sources of false accusations also include custody disputes where children are led or persuaded into giving testimony of abuse by the parent with whom they do not reside. There is reason to think that the frequency of false rape allegations is also high. For example, Kanin (1994), in a small 
American metropolitan community, studied 109 allegations of forcible rape of which $41 \%$ were determined by the police to be false on the basis of both independent evidence and confession. These false allegations appeared to serve three major functions for the complainants: providing an 'alibi', seeking revenge and obtaining sympathy and attention.

For obvious reasons there are no good epidemiological data on the frequency of false accusations of various types, but the occurrence of court cases based on fantastic allegations - now ending more and more often in acquittal or in damages against the therapist's accuser - is common in nearly every community of more than 30000 people across North America. Pendergrast calculates on the basis of the numbers of therapists who claim to recover memories actively that on a conservative estimate as many as $1 \%$ of the population of the USA have been given such false beliefs and adopted them, which therefore may have disrupted at least one in 25 families.

It seems plausible that something similar is happening in Britain from the number of cases coming to notice in the press, and also from the attitudes reported by the British Psychological Society (Andrews et al, 1995) where, in a sample of 810 members of the society, $97 \%$ believed in the essential accuracy not only of recovered memories, but also of satanic ritual abuse reports. Fifty-three per cent believed such memories 'sometimes', 38\% 'usually' and 6\% 'always'. Twenty-three of the respondents had patients who had recalled memories from total amnesia while in therapy with them during the previous year. If 200 British psychologists (not counting psychiatrists and others, including marriage guidance counsellors and lay therapists) each see about 50 new patients a year and recover memories in $25 \%$, we can expect about 2500 new cases per annum from that source alone. That would be much lower than Pendergrast's figures which include psychiatrists, psychologists and licensed counsellors, but still be quite large enough to make a sizeable impression upon the health of the public.

\section{'Disclosure' and challenge}

False allegations may be revealed gradually with some hints, or may occur suddenly. The intending accuser quite often solicits support from another sibling, generally suggesting to that sibling that he or she has been abused as well, and that they might recall the accuser having been abused - especially if the accuser is younger than the other siblings. On the instructions of therapists and following the model in The Courage to Heal, patients have been told that recovery depends partly upon confronting
Box 4. Widespread accusations have been made in the context of

Day nurseries/pre-schools/crèches Non-custodial/separated parents Adult accusations of rape

the perpetrator. Typically, the confrontation is set up so that the parents or other accused relatives are told they can see their child, the child will have something to say to them, but comment in response will not be acceptable. They may be deliberately deceived about the tenor of the meeting and then confronted very harshly. If such a meeting takes place, the accuser may read a prepared statement describing the abuse and the need for apology, confession and emotional reparation. Perhaps more often, the split is gradual and a confrontation in person does not occur, but demands are made for confession, for example, "Until you admit how much you abused me I can have nothing more to do with you". The withdrawal of the children is frequently accompanied by the blocking of access to grandchildren. Birthday cards and presents either to the accusing child or to the grandchildren may be returned. Sometimes gifts to the grandchildren are permitted, but at other times not. Accused fathers or mothers may be told that they have themselves repressed their memories of abusing their child, even though they have no memories - so perhaps they did do something. In Ontario, at least one court judgement accepted such an allegation.

It has been said that the loss of a child in this way is as bad as a loss by death. Perhaps a death by suicide with a hostile note blaming the family would be the equivalent. Families whose children make accusations and cut themselves off become distraught for several reasons. First, the loss is grievous. Also, there may be legal proceedings or the threat of them. Proceedings may begin with a criminal case and if the criminal case fails (and more likely, if it is successful), proceed to a civil suit. This is much less common than it was five years ago. The cost even of a law suit which does not go to trial can be substantial, especially for parents who are retired. If a 35-year-old daughter makes accusations about something that happened 20 years ago, her parents are likely to be in their $60 \mathrm{~s}$ or $70 \mathrm{~s}$. To some extent this pattern is an assault on the elderly who are poorly placed to respond. However, a small number of high-profile law suits in return, beginning with the Ramona case (Johnston, 1997) have involved parents suing their children's therapists. In larger numbers of cases 'retractors' (former accusers who have given up their false memories) have success- 
fully sued therapists for malpractice, many cases being settled out of court.

\section{Impact on psychiatry}

The impact of these developments on psychiatry has been enormous. It has placed the profession in a very embarrassing position, as some of the propagation of false memories has been undertaken by psychiatrists, and it has led to clear divisions. These divisions occurred first in North America and then in Britain and elsewhere, between academic psychologists and psychiatrists on one side, and many clinical practitioners on the other. Bitter arguments have ensued. More importantly in this connection, the burgeoning of the false memory phenomenon has resulted in a need to take a new look at the theory of repression which is now undergoing widespread discussion and is under serious scientific attack.

\section{Problems with repression}

It has long been known that efforts in experimental psychology have completely failed to produce controlled evidence of the occurrence of repression. Holmes $(1974,1990)$ established this in the course of his own investigations and in a thorough review of the literature, and pointed out that the failure to prove it after 60 years suggested that the concept was not worth maintaining. The only evidence that remains for it is anecdotal. The American Psychiatric Association (1993) in a statement on the issue of false memories, stated that repression did occur, but was unable to provide convincing references. On examination of a list of 31 references none adequately demonstrated that it took place. Meanwhile, studies in cognitive psychology have shown very clearly that memory is highly malleable and is a reconstructive process, not to be compared with the replaying of a disc or the review of an engraving or a videotape. The hypothesis that memory - so subject to attrition with time and so liable to revision by motive - can be recovered in a pristine form or even in a $50 \%$ accurate state after years of neglect, inattention or suppression becomes untenable. Hence, the fundamental notion of repression has come under a serious challenge which requires much conceptual rethinking in psychiatry - rethinking that is still to be done. This is not to say that motivated forgetting or preferential attention, or other phenomena that have been explained as repression, do not occur: only that the comfortable and easy dynamic explanations are gravely suspect. An immediate loss of memory, such as a fugue or a hysterical amnesia, may still occur acutely, but we can no longer necessarily explain them in classical psychoanalytical terms. Such explanations are philosophically suspect and still have not been validated scientifically (Merskey, 1995). Even the hallowed Charcotian diagnosis of a hysterical fugue state is now questioned and seems likely to be a creative construction by Charcot, his colleagues and his patients (Hacking, 1996).

This may be discomfiting to some readers, but may encourage others in at least one respect. Psychiatrists who tried according to traditional advice to conduct intensive psychotherapy with patients, and who were sparing of their interpretations or of showing their hand, may rarely have produced recovered memories in their patients. The training of psychiatrists in Britain for some decades has emphasised the importance of not suggesting material to patients. Practising on those lines it was rare to find recovered memories, if they occurred at all, although patients might disclose occasional topics that they had been aware they were holding back. The efflorescence of dramatic recovered memories only appeared as the restraints of suggestion were abandoned and the established canons of psychotherapy violated.

\section{Prevention}

In social changes of this scale, prevention is the best hope of producing radical improvement quickly. The most effective means of prevention so far, leading to a reduction in the numbers of people with recovered memories accusing their families, has been widespread publicity in the electronic and print media. Impressive television programs in the USA, Canada and Britain, and large numbers of articles in newspapers and in magazines, as well as books for both the lay reader and professionals, have led to a decrease in the numbers of cases presenting. It is certainly hard to imagine now that people will come forward as readily as previously to make accusations based on the recovery of memories of long past incidents of which they had no intervening recollection. The sooner this happens in all cases the better, since it will allow more opportunity to discriminate and identify genuine cases of abuse. In any case, the print and electronic media have been followed by professional bodies which, in some cases, have adopted quite effective guidelines or statements on the topic. Thus, the American Medical 
Association (1994) stated that recovered memories of childhood sexual abuse are of uncertain authenticity, should be subject to verification and are fraught with the problem of potential misapplication. It had already objected to the use of hypnosis in the past. The Australian Psychological Society (1994) emphasised that psychologists should be alert to the susceptibility of patients to subtle suggestions and reinforcement, whether those communications are intended or unintended, and recommended care in all cases with recovered memories. The Canadian Psychiatric Association (1996) noted that sexual abuse at any age is deplorable and unacceptable and should always be given serious attention and that all spontaneous reports should be treated with respect and concern. It concluded, as well, that reports of recovered memories of sexual abuse may be true, but great caution should be exercised before acceptance in the absence of solid corroboration.

The most recent recommendations for good practice by the Royal College of Psychiatrists' Working Group on Reported Recovered Memories of Child Sexual Abuse (1997) are in line with the cautions issued by the other agencies. They begin with an explicit recognition of the severity and significance of child sexual abuse and the suffering experienced as a result, both in childhood and in adult life. The College advises that past sexual abuse in the absence of memories of those events cannot be diagnosed through a check-list of symptoms. Memory recovery techniques based upon the expectation of past sexual abuse of which the patient has no initial recall are explicitly rejected. Such techniques: "...may include drug-mediated interviews, hypnosis, regression therapies, guided imagery, 'body memories', literal dream interpretation and journaling" and are all firmly rejected. Forceful or persuasive interviewing techniques are likewise dismissed as not acceptable in psychiatric practice and doctors are told to be aware that even unintended subtle suggestions may produce serious ill-effects. The Working Group also states that: "...it is rarely appropriate to discourage or even to forbid the patient from having contact with the alleged abuser or family members". The College offers further warnings on multiple personality disorder. It states:

"There seems little doubt that some cases of multiple personality are iatrogenically determined and psychiatrists should be careful to ensure that they do not directly encourage patients to develop 'alters' in whom they may invest aspects of their personality, fantasies or current problems".

The net result of the College's recommendations is to make it clear that recovered memory therapy, along with most of its works, is no longer professionally acceptable. Considering the little evidence of proof and the substantial evidence of harm to many individuals that appears to have resulted from recovered memory therapies (Pendegrast, 1997) this is an inevitable conclusion.

The scientific evidence for the guidelines has been put forward in a peer-reviewed article by four of the six members of the original committee (Brandon et al, 1998).

The stance of the professional societies is thus increasingly to discourage the use of recovered memory techniques, particularly including hypnosis, relaxation with guided imagery, narcoanalysis, dream analysis and any type of psychotherapy in which the patient is given instructions to find lost material about sex which was previously not available. The stronger position statements are unequivocally helpful in promoting disbelief in alleged recovered memories, leading to a reduction in their presentation. Professional education is therefore called for at all levels, from psychiatrists to psychologists, social workers, nurses and all other practitioners involved in treating patients psychotherapeutically. This should not prove difficult, since despite heated objections from some therapeutic quarters, the trend of press and public opinion and the position of professional colleges or associations is to recognise that false accusations of sexual abuse based on recovered memories are, at the least, implausible.

Legal rules can also be important in prevention. In America, the fact that Gary Ramona was able successfully to sue his daughter's former therapists for implanting false allegations had a powerful influence on the professions of psychiatry and psychotherapy. Technically, the greatest interest for psychiatry lies in the fact that the theory of repression which has become dominant over more than 100 years is now again in the melting pot. This is not to say that we should not find room for a theory which deals with differential attention, motivated neglect of topics, supposed psychogenic amnesia and so forth, but rather that the simple, strong theory of repression of unpleasant material into the unconscious mind is no longer an acceptable version of what happens when people develop hysterical or dissociative symptoms.

\section{Treatment}

Two types of individuals attend for treatment. Accused parents are much more common than retractors, but retractors are increasing in numbers. More than 1000 former accusers contacted the FMSF in Philadelphia or made inquiries of it in the period from 1992 to 1996. 


\section{Treating those accused}

Support for parents in this painful situation in Britain is provided by the False Memory Society. It is often hard for the parents to learn of what they are said to have done. One reply to the comment that nothing has been said as to what was specifically alleged has been 'you know'. The mere fact of knowing that others have been placed in the same situation, the improbability of the allegations, the increasing recognition of the harm caused by false accusations, all help to make things easier for the falsely accused.

The doctor seeking to help accused patients in this dilemma needs first to establish the usual general information that one would seek for any patient with an emotional problem: personal history, family history, current stresses, etc. An account of the life of the accusing child and other children is also required. Details of the allegations will need to be discussed insofar as they are known and the existence of any evidence or lack of it either for or against the accusations. To the best of my knowledge I have been consulted by individuals who were accused on the basis of false or far-fetched allegations. I have, however, twice seen instances where an accused man at the behest of his lawyer had pleaded guilty to a minor charge because he could not face a trial. In both instances the admission of guilt in legal proceedings (even though accompanied outside the legal proceedings by a firm and plausible denial of responsibility) was successfully held against the accused person in subsequent proceedings. One of these cases concerned a doctor whose patients accused him.

It is fair to express an opinion to patients as to the strength or weakness of the evidence seen from the physician's point of view, but not of course to indicate that this is a conclusion that will necessarily hold up in a law court, and doctors who have doubts about the likely innocence of the accused persons should of course adapt their conduct of the case to their view of that matter. This might be done by saying that one can go along with the patient in regard to the strength of their feelings and the distress that they are experiencing, but that one is unable to reach a final conclusion on a matter which in the end is likely to be taken to a law court. To the innocent accused that will be seen as a very unfeeling way of responding. Faced with this dilemma as to what to do about a patient who protests innocence and whom one cannot exonerate (most likely because of incomplete information) a second opinion would probably be in order.

Parents frequently seek advice on what to do about their accusing child, whether they should attempt to contact them, how they may approach them, what possibilities exist to establish reconciliation and so forth. There is no single way to respond to this question successfully. In some cases the parents themselves do not wish to make any moves, or cannot. The best advice then is to encourage and support. An aggressive action may feel right, but not serve any useful purpose and can be counter-productive. Firm and consistent adherence to telling the child when the opportunity exists - that the parent still loves them and at the same time will not make false acknowledgements of what occurred is probably the best single guideline. If legal proceedings are being talked about, care should be taken in any approaches that are made and legal advice to the parents is essential. The most encouraging and delicate issue sometimes arises when parents are approached by their child indirectly or even directly, but tentatively, with some hints of potential reconciliation without the child admitting that she was wrong. Individuals differ in how they want to handle this, but most agree that they would sooner see their child than not, and that the willingness to make contact, even without an admission of error, is a positive step forward which may lead to better things. If the communicating child does not wish to talk about the topic, the majority seem to find that it is better not to do so and that relationships can be reestablished, at least to some extent.

\section{Treating accusers or retractors}

Accusers who are not ready to forgive their parents, or have not considered that they may have been innocent, probably will not seek the sort of traditional medical help which most psychiatrists provide, that is, sympathetic assistance in reconstituting the relationship. They will more likely want to continue accusing their parents, and to frequent therapists who support them in that. Where accusers begin to express doubts, the doctor then can review the history with the patient, explore the grounds for doubts and, in all fairness, support those doubts if they are justified, and not if they are not. One can attempt to support reconciliation or mediation where some accusation is still held against the parent, but not strongly and not at the serious end of the spectrum of accusations of abuse.

Retractors are generally brittle. If they have recognised fully what they have done and what has happened to them, they feel mortification and shame at their actions and at the harm caused. They may be extremely sensitive as to whether or not they will be 'forgiven'. They are also likely to be at least annoyed, if not angry, at the therapists. Opportunities to treat retractors are limited, but from the experience available, it is well worth evaluating 
patients to see if there is still a significant psychiatric problem, particularly bipolar affective disorder, which may be amenable to medication. McElroy \& Keck (1995) have described the successful treatment of patients whose false accusations were based upon obsessional, compulsive ruminations. Hays (1992) has described four cases of patients who made genuinely sincere false accusations based on experiences associated with narcolepsy and cataplexy. The treatment in these latter instances revolves around first establishing the genuine nature of the patient's belief; second, demonstrating the relationship to hypnagogic or hypnopompic phenomena; and third, treating appropriately both in terms of somatic care and psychological support. Such patients may express their regrets and their recognition of what happened. In all cases, emotional support for the retractor and a patient attitude to the retractor and the family is the method most likely to be successful.

Any psychiatrist treating retractors is bound to have an interest in finding out what the patient actually believed, what they went through and how they came to make the accusations. Usually by the time such a person comes to a psychiatrist, much of the information will be available and will be freely volunteered. It is reasonable to inquire gently into aspects of these matters that have not been covered and to try and help to resolve them suitably.

In the end the treatment of the retractor will depend upon care, sympathy and comprehensive psychiatric skills.

\section{References}

American Medical Association (1994) Memories of Childhood Abuse. Childhood Sexual Abuse Report (5-A-94). Chicago, IL: AMA.

American Psychiatric Association (1993) Statement Approved by the Board of Trustees. Washington, DC: APA.

Andrews, B., Morton, J., Bekerian, D. A., et al (1995) The recovery of memory in clinical practice: experiences and beliefs of British Psychological Society practitioners. Psychologist, 5 May, 209-214.

Australian Psychological Society (1994) Guidelines Relating to the Reporting of Recovered Memories. Carlton, Victoria: Australian Psychological Society.

Bass, E. \& Davis, L. (1988) The Courage to Heal. New York: Harper \& Row.

Brandon, S., Boakes, J. P., Glaser, D., et al (1998) Recovered memories of childhood sexual abuse. British Journal of Psychiatry, 172, 296-307.

Canadian Psychiatric Association (1996) Position statement. Adult Recovered Memories of Childhood Sexual Abuse. Canadian Journal of Psychiatry, 41, 305-306.

False Memory Syndrome Foundation (1993) Family Survey: Results. Philadelphia, PA: FMSF.

Hacking, I. (1996) Les aliénés voyageurs: How fugue became a medical entity. History of Psychiatry, 7, 425-449.

Hays, P. (1992) Sincere but false accusations of sexual assault made by narcoleptic patients. Medico-Legal Journal, 60, 265-271.
Holmes, D. S. (1974) Investigations of repression: differential recall of material experimentally or naturally associated with ego threat. Psychological Bulletin, 81, 632-653.

- (1990) The evidence of repression: An examination of sixty years of research. In Repression and Dissociation (ed. J. L. Singer), pp. 85-102. Chicago, IL: University of Chicago Press.

Johnston, M. (1997) Spectral Evidence and the Ramona Case. Incest, Memory and Truth on Trial in the Nappa Valley. Boston, MA: Houghton Mifflin.

Kanin, E. J. (1994) False rape allegations. Archives of Sexual Behavior, 23, 81-92.

McElroy, S. L. \& Keck, P. E., Jr (1995) Recovered memory therapy: false memory syndrome and other complications. Psychiatric Annals, 25, 731-735.

Merskey, H. (1995) The Analysis of Hysteria. Understanding Conversion and Dissociation (2nd edn). London: Gaskell.

Pendergrast, M. (1997) Victims of Memory: Incest Accusation and Shattered Lives. London: Harper Collins.

Royal College of Psychiatrists' Working Group on Reported Recovered Memories of Child Sexual Abuse (1997) Recommendations for good practice and implications for training, continuing professional development and research. Psychiatric Bulletin, 21, 663-665.

\section{Multiple choice questions}

1. The false memory syndrome first emerged:

a in poorly educated individuals

b in patients with a known history of physical abuse

c in patients receiving special treatment by psychotherapists

d outside therapy meetings

e with none of the above.

2. Memories of supposed childhood abuse have a greater likelihood of being false if:

a they relate to a time when the accuser was less than four years old

b they are said to have been lost for years and then recovered

c they developed under the influence of a therapist

d suggestive procedures, including reading the book The Courage to Heal were urged upon the patient

e none of the above is true.

3. Recovered memory allegations frequently arise after a special type of recovered memory psychotherapy:

a if the treatment is conducted by all manner of practitioners including unqualified persons

b if the treatment is founded upon the theory of repression

c if procedures such as hypnosis, guided imagery, dream interpretation are employed,

$\mathrm{d}$ if therapists frequently recommend that the patient cuts off all contact with any relevant person who will not confirm or acknowledge being an abuser

e in all of the above circumstances. 
4. Effective treatment of an accuser harbouring false memories involves:

a willingness of the patient to suspend judgement and to make contact with someone who has a sceptical but tolerant approach

b willingness of the psychiatrist to listen to allegations which demonstrate a need for adequate corroboration

c the ability of the physician to conduct a global psychiatric interview and make specific diagnoses and recommendations

d the ability to treat the patient for a variety of specific diagnoses

e none of these statements is true.
5. Recovered memory treatment has included:
a regression to infantile experiences
b emergence of multiple personality disorder
c recollections of past lives
d experience of alien abductions
e all of the above.

\begin{tabular}{|ccccccccc|}
\hline \multicolumn{2}{|c}{ MCQ } & answers & & & & & & \\
1 & 2 & 3 & & 4 & & 5 & \\
a F & a & T & a & T & a & T & a & T \\
b F & b & T & b & T & b & T & b & T \\
c T & c & T & c & T & c & T & c & T \\
d F & d & T & d & T & d & T & d & T \\
e F & e & F & e & T & e & F & e & T \\
\hline
\end{tabular}

\section{Commentary}

\section{Peter Whewell}

The study of trauma is inherently political. It is hard for psychiatrists to maintain an open mind, to respect and tolerate uncertainty and to maintain standards of scrutiny of scientific data when there are powerful political and emotional pressures to take up a polarised view of recovered memories of child sexual abuse. The two polarisations that have arisen are of recovered memories as invariably historically accurate versus recovered memories as invariably false and created by suggestion by clinicians. Current evidence suggests the psychiatrist should take up a cautious position somewhere between these two poles.

Merskey does not present empirical evidence for the existence of FMS. He only quotes figures calculated by Prendergast, who is a journalist (not a clinician) who has been accused of abuse by his daughter, and thus has a particular position to advocate. The FMSF states that there are several thousand cases in the USA and a thousand cases in Britain, but their claims are based upon their own conclusions from their own data. Pope \& Brown (1996) make the following comment:

"Those claiming that scientific research has validated FMS and identified an epidemic have a responsibility to disclose the methods for determining that each case involved a memory that was objectively false. The peer-reviewed scientific literature still lacks adequate information about this methodology. It continues to be unclear if the protocol of any research purporting to validate FMS diagnosis in large numbers of persons used any criticism other than the decisionrule that all recovered memories of abuse are inherently false".

The British Psychological Society (1995) concluded from an independent examination of the British False Memory Foundation records that the FMSF's claims that accusers fitted a certain profile,

Dr Whewell is a consultant psychotherapist (Regional Department of Psychotherapy, Newcastle City Health Trust, Claremont House, Off Framlingham Place, Newcasle upon Tyne NE2 4AA) currently working in a team specialising in treating personality disorders. He was a member of the Royal College of Psychiatrists' Working Group on Reported Recovered Memories of Child Sexual Abuse. 